\title{
On the Application of Steam-Driven Water Jets for Propulsion Purposes*
}

\author{
J. M. Burgers ${ }^{1}$ and A. Ghaffari :
}

\begin{abstract}
Calculations have been made concerning the momentum that can be given to a jet of water by mixing it with a jet of high-speed steam. Apart from an application of the equations of momentum and enthalpy, this raises questions concerning the speed of condensation and the acceleration of the water.
\end{abstract}

\section{Introduction}

Basic equations for the change of temperature and of momentum to be expected when jets of steam and water are mixed have been given by Chiarulli and Dressler [1]. ${ }^{3}$

The present authors extended these calculations to a case where momentum must be communicated to a jet of water by mixing it with a jet of highspeed steam in such a way that complete condensation of the steam will take place. It was thought that condensation under constant pressure would have certain advantages. On the one hand there is a much smaller loss of useful momentum, while on the other hand the thermodynamic aspect of the condensation becomes simpler. It was also thought that there would be less chance for the appearance of shocks. In order to obtain condensation under constant pressure, the chamber in which the condensation takes place must have a sectional area decreasing in the direction of the flow (as is applied in the injector for steam locomotives), according to some law that must be determined.

It was thought useful to have a concrete example in mind with definite numerical values. It was assumed therefore that the pressure in the mixing chamber should be kept equal to $0.8 \mathrm{~atm}$.

The water is supposed to enter into the mixing chamber in the axial direction, with a velocity $u^{\prime}=10 \mathrm{~m} / \mathrm{sec}$ and a temperature of $T^{\prime}=20^{\circ} \mathrm{C}$. The enthalpy of the water then is $H^{\prime}=20.1 \mathrm{kcal} / \mathrm{kg}$, the density $\rho^{\prime}=998 \mathrm{~kg} / \mathrm{m}^{3}$.

Data have been taken from W. Koch and K. Schmidt, VDI-Wasserdampftafeln (Springer-Verlag, 1952); since these data are presented in technical units, we must make use to a certain extent of the system in which the kilogram is taken as the unit of weight or force. We shall write $\mathrm{kg}^{*}$ in this case, and reserve the notation $\mathrm{kg}$ when it refers to mass.

The steam used as a driving force is supposed to be obtained from a boiler where the temperature is about $165^{\circ} \mathrm{C}$ and the pressure $7.5 \mathrm{~atm}$ (saturation pressure for this temperature). After coming from the boiler the steam is superheated to $T_{0}=360^{\circ} \mathrm{C}$, the pressure remaining $p_{0}=7.5 \mathrm{~atm}$. The steam

\footnotetext{
*The preparation of this paper was supported by the Office of Naval Research, U. S. Navy.

i Guest worker, National Bureau of Standards, from American University; and University of Maryland

2 National Bureau of Standards, and on leave from Teheran University.

3 Figures in braekets indicate the literature references at the end of this paper.
}

then has an enthalpy $H_{0}=759.4 \mathrm{kcal} / \mathrm{kg}$. It will be assumed that the expansion of the steam from $7.5 \mathrm{~atm}$ to 0.8 atm occurs without friction losses and without change of entropy. If losses and entropy change cannot be avoided, we suppose that they are compensated for by a suitable increase of $T_{0}$ and $p_{0}$, so that we shall still have the same data for the expanded state as are given below. After expansion the steam will then have the following properties:

$$
\begin{aligned}
& \text { pressure } p^{\prime \prime}=0.8 \text { atm }=8,000 \mathrm{~kg} * / \mathrm{m}^{2} \\
& \text { temperature } T^{\prime \prime}=99.0^{\circ} \mathrm{C} \\
& \text { density } \rho^{\prime \prime}=0.462 \mathrm{~kg} / \mathrm{m}^{3} \\
& \text { enthalpy } H^{\prime \prime}=639.4 \mathrm{kcrl} / \mathrm{kg} \\
& \text { velocity } u^{\prime \prime}=1,003 \mathrm{~m} / \mathrm{sec} \text {. }
\end{aligned}
$$

It is assumed that also the velocity $u^{\prime \prime}$ of the steam is directed axially.

The entrance area of the mixing chamber will be denoted by $A$; of this the part $A s$ is taken in by the water jet, and the part $A(1-s)$ by the steam jet.

We write $A_{m}$ for the sectional area of the mixing chamber at the point where complete condensation has been reached; $u_{m}$ for the speed of the water when all is condensed; $\rho_{m}$ for the density of this water, for which we shall use a mean value $\rho_{m}=985$ $\mathrm{kg} / \mathrm{m}^{3}$; further $T_{m}$ for its temperature, $H_{m}$ for its enthalpy. We note that the mechanical equivalent of heat in technical units is $J=427 \mathrm{~kg}^{*} \mathrm{~m}$ per kcal; and that $g=$ acceleration of gravity $=9.8 \mathrm{~m} / \mathrm{sec}^{2}$.

\section{Basic Equations for the Mixing Process}

The following equations hold for the mixing process:

Equation of continuity:

$$
A s \rho^{\prime} u^{\prime}+A(1-s) \rho^{\prime \prime} u^{\prime \prime}=A_{m} \rho_{m} u_{m} .
$$

When numbers are inserted, we solve for $\left(A_{m} / A\right) u_{m}$ and obtain:

$$
\left(A_{m} / A\right) u_{m}=0.47+9.56 s,
$$

Equation of momentum:

$$
A s \rho^{\prime} u^{\prime 2}+A(1-s) \rho^{\prime \prime} u^{\prime \prime 2}=A_{m} \rho_{m} u_{m}^{2} .
$$


Inserting numerical values we find:

$$
\left(A_{m} / A\right) u_{m}{ }^{2}=472-372 s .
$$

Equation of enthalpy:

$$
\begin{gathered}
A s \rho^{\prime} u^{\prime}\left(H^{\prime}+u^{\prime 2} / 2 g J\right)+A(1-s) \rho^{\prime \prime} u^{\prime \prime}\left(H^{\prime \prime}+u^{\prime \prime 2} / 2 g J\right) \\
=A_{m} \rho_{m} u_{m}\left(H_{m}+u_{m}{ }^{2} / 2 g J\right) .
\end{gathered}
$$

Inserting numerical values we arrive at:

$$
\left(A_{m} / A\right) u_{m}\left(H_{m}+u_{m}{ }^{2} / 2 g J\right)=258-156 s .
$$

From eqs (4) and (2) we can obtain $u_{m}$; from (6) and (2) we obtain $H_{m}+u_{m}^{2} / 2 g J$ and then $H_{m}$ itself; from the latter quantity the temperature of the water can be found. It is also possible to find $\left(A_{m} / A\right)$.

The condensed water has the speed $u_{m}$ and the pressure $p_{m}=p^{\prime}=8,000 \mathrm{~kg} * / \mathrm{m}^{2}$. When it is to be used for propulsion, it may have to be driven out against a higher pressure $p_{e}$. In such a case it will be appropriate after the mixing to make the water flow through an expanding duct, in which the velocity decreases from the value $u_{m}$ to a value $u_{e}$, adjusted so that the pressure will increase from $p_{m}$ to $p_{e}$. In what follows we have assumed: $P_{e}=2.0$ atm $=$ $20,000 \mathrm{~kg} * / \mathrm{m}^{2}$. We then find:

$$
u_{e}^{2}=u_{m}^{2}-239(\mathrm{~m} / \mathrm{sec})^{2} .
$$

Formulas for other values of $p_{e}$ can easily be derived.

The equations can be worked out for various values of $s$. After some trials it was found that $s=0.5$ gave a convenient case. Larger values of $s$ (meaning that more water is admitted in the mixing chamber in comparison with the steam) make the exit speed rather low; smaller values of $s$ (meaning that more steam is used in comparison with the water) make the final temperature higher and may lead to incomplete condensation. With $s=0.5$ the following results are obtained:

$$
\begin{aligned}
u_{m} & =54.5 \mathrm{~m} / \mathrm{sec} \\
u_{e} & =52.3 \mathrm{~m} / \mathrm{sec} \\
H_{m} & =52.9 \mathrm{kcal} / \mathrm{kg} \\
T_{m} & =52.9^{\circ} \mathrm{C} \\
A_{m} / A & =0.096 .
\end{aligned}
$$

To the temperature $T_{m}$ corresponds a saturation pressure of $1,450 \mathrm{~kg} * / \mathrm{m}^{2}$. Since the pressure in the mixing chamber is $8,000 \mathrm{~kg} * / \mathrm{m}^{2}$, it was thought that there would be no danger for incomplete condensation provided the time for condensation is not made too short (see section 4).

\section{Momentum and Efficiency of the Issuing Jet}

The total mass flow of water in the issuing jet is: $A_{m} \rho_{m} u_{m} \mathrm{~kg} / \mathrm{sec}=A_{m} \gamma_{m} u_{m} / g$ technical units of mass per second.
Here $\gamma_{m}$ is used to represent the specific weight of the water, which, when expressed in $\mathrm{kg}^{*} / \mathrm{m}^{3}$, is given by the same number 985 as for its density in $\mathrm{kg} / \mathrm{m}^{3}$.

When the jet is applied to drive an underwater object with a speed of $V \mathrm{~m} / \mathrm{sec}$, the usual arrangement will be that the water is taken out of the surroundings, where it had the speed $V$ relative to the object, while it is reissued as a jet with the speed $u_{e}$ relative to this object. Hence the thrust to be obtained is given by:

$$
\text { thrust }=\left(A_{m} \gamma_{m} u_{m} / g\right)\left(u_{e}-V\right) \mathrm{kg}^{*} .
$$

The useful work done in unit of time is:

$$
\text { power }=\left(\begin{array}{lll}
A_{m} & \gamma_{m} & \left.u_{m} / g\right) \\
\left(u_{e}-V\right) V \mathrm{~kg} * \mathrm{~m} / \mathrm{sec} .
\end{array}\right.
$$

It may be possible to choose $V$ so that this expression has a maximal value; this occurs when $V=\frac{1}{2} u_{e}$. We then find:

$$
\begin{gathered}
\text { thrust }=\frac{1}{2}\left(\begin{array}{llll}
A_{m} & \gamma_{m} & \left.u_{m} / g\right) & u_{e} \mathrm{~kg}^{*} \\
\text { power }=\frac{1}{4}\left(A_{m}\right. & \gamma_{m} & \left.u_{m} / g\right) & u_{e}^{2} \\
\mathrm{~kg} & * \mathrm{~m} / \mathrm{sec} .
\end{array}\right.
\end{gathered}
$$

Inserting numerical values with $s=0.5$, we arrive at:

$$
\begin{gathered}
\text { thrust=approx } 13,800 \mathrm{~A} \mathrm{kg*} \\
\text { power=approx } 360,000 \mathrm{~A} \mathrm{kg*m} / \mathrm{sec} .
\end{gathered}
$$

In these formulas $A$ is expressed in $m^{2}$. When the entrance area of the mixing chamber is taken as $100 \mathrm{~cm}^{2}=0.01 \mathrm{~m}^{2}$, the values become:

$$
\text { thrust=approx } 138 \mathrm{~kg} *
$$

$$
\text { power=approx } 3,600 \mathrm{~kg}^{*} \mathrm{~m} / \mathrm{sec} \text {. }
$$

In order to obtain a rough idea concerning the efficiency of the arrangement, we will consider only the energy used for the steam production. We have assumed that the water needed for this purpose is taken from the surroundings, at the temperature of $20^{\circ} \mathrm{C}$, so that the enthalpy is $20.1 \mathrm{kcal} / \mathrm{kg}$. It follows that per $\mathrm{kg}$ water to be turned into steam, the enthalpy difference $H_{0}-H^{\prime}=759.4-20.1=739.3$ kcal is needed. Since the mass of the steam needed per second is given by $A(1-s) \rho^{\prime \prime} u^{\prime \prime}=A(1-s) \times 463$ $\mathrm{kg} / \mathrm{sec}$, the energy required per second is:

$$
A(1-s) \times 463 \times 739.3 \times 427 \mathrm{~kg}^{*} \mathrm{~m} / \mathrm{sec} .
$$

With $s=0.5$ this becomes: $A \times 0.73 \times 10^{8} \mathrm{~kg}^{*} \mathrm{~m} / \mathrm{sec}$, and for $A=0.01 \mathrm{~m}^{2}$ the energy required (at least) is $730,000 \mathrm{~kg} * \mathrm{~m} / \mathrm{sec}$. This would give a maximal efficiency of

$$
3,600 / 730,000=0.0049 .
$$

The low value of the efficiency should not be used as a measure for the merits or demerits of the system, since its merit is in the simplicity of operation. 


\section{Speed of Condensation}

For complete condensation not only a sufficient difference must be maintained between the pressure in the mixing chamber and the saturation pressure at the temperature after the condensation, but there is involved also a question of time.

It is desirable that the condensation should require not too much time, since otherwise a mixing chamber of considerable dimensions will be needed in view of the velocity of the water which rises from $u^{\prime}=10$ $\mathrm{m} / \mathrm{sec}$ to $u_{m}=54.5 \mathrm{~m} / \mathrm{sec}$. In order to have a definite case it was thought that each element of volume of the water should stay not longer than 0.1 sec in the mixing chamber. The problem is whether complete condensation will be possible under this condition. Because we have condensation of steam in the presence of water, the question of obtaining a sufficient number of condensation nuclei does not present itself, but the important matter is to have a sufficient surface area of the water in order to make rapid condensation possible.

The speed of condensation depends on two factors: (a) Whether the difference between the pressure in the steam and the saturation pressure at the water surface will accelerate the steam sufficiently rapidly in order that it can reach the water surface within the time limit set above; and (b) whether the heat liberated by the condensation can flow off towards the interior of the water sufficiently rapidly. The latter problem depends on heat conduction and a simple estimate gave the impression that this was the really important question.

In treating the problem of heat conduction into the interior a mathematical difficulty presents itself in consequence of the circumstance that the condensation adds water to the already existing surface, so that the surface where condensation occurs displaces itself with time. For the case of a plane surface a treatment will be given (a) based on the ordinary solution of the one-dimensional heat equation, in which this displacement is neglected; and (b) on a solution in which the displacement is taken into account according to a method indicated by I. I. Kolodner [2].

The equation for the heat conduction in one dimension is,

$$
\frac{\partial T}{\partial t}=\kappa \frac{\partial^{2} T}{\partial y^{2}}
$$

where $y$ is the distance measured from the surface of the water inwards. Here $\kappa=\lambda / \rho C$, where $\lambda$ is the thermal conductivity of the water; $\rho$ is the density and $C$ is the specific heat. For $\lambda$ we can take (approximately) $1.4 \times 10^{-3} \mathrm{cal} \mathrm{sec}^{-1} \mathrm{~cm}^{-1}{ }^{\circ} C^{-1}$; in c-g-s units $\rho=1$ and $C=1$, so that $\kappa$ has the value $1.4 \times 10^{-3} \mathrm{~cm}^{2} \mathrm{sec}^{-1}$.

When the initial temperature of the water is $T^{\prime}\left(=20^{\circ} \mathrm{C}\right)$ and the surface on which the steam condenses acquires a temperature $T_{s}\left(=93^{\circ} \mathrm{C}\right.$, the saturation temperature for the pressure of $0.8 \mathrm{~atm}$ ), the appropriate solution of the equation is,

$$
T=T^{\prime}+a\left(1-\operatorname{erf} \frac{y}{2 \sqrt{\kappa t}}\right)
$$

When we neglect the displacement of the surface, we must have $T=T_{s}$ for $y=0$, which gives,

$$
a=T_{s}-T^{\prime}=73^{\circ} \mathrm{C} \text {. }
$$

The heat flow to the interior then becomes $\left(\right.$ per $\mathrm{cm}^{2}$ and per sec)

$$
q=-\lambda\left(\frac{\partial T}{\partial y}\right)_{0}=\rho C\left(T_{s}-T^{\prime}\right) \sqrt{\frac{\kappa}{\pi t}} .
$$

The heat flowing to the interior in the time $t$ is,

$$
q_{t}=\frac{2}{\sqrt{\pi}} \rho C\left(T_{s}-T^{\prime}\right) \sqrt{\kappa t} \cong 3.08 \sqrt{t} \mathrm{cal} / \mathrm{cm}^{2} .
$$

Taking $t=0.1$ sec we find,

$$
g_{t}=0.975 \mathrm{cal} / \mathrm{cm}^{2} .
$$

The amount of heat to be taken up by the water is found as follows: There enters into the mixing chamber per second, $A(1-s) \rho^{\prime \prime} u^{\prime \prime} \mathrm{kg}$ steam. ${ }^{4}$

This steam is condensed into water with a temperature of at most $53^{\circ} \mathrm{C}$ (for $s=0.5$ ). We take as mean temperature of the water: $\left(20^{\circ}+53^{\circ}\right) / 2=36^{\circ} .5$. The steam has the enthalpy $H^{\prime \prime}=639.4 \mathrm{kcal} / \mathrm{kg}$. The heat to be taken up by the water entering into the mixing chamber is given by the loss in enthalpy plus kinetic energy of the steam on condensation. Since the enthalpy plus kinetic energy of a given mass of steam remains the same as its value in the boiler, say $759.4 \mathrm{kcal} / \mathrm{kg}$, and since the kinetic energy of the water is $0.1 \mathrm{kcal} / \mathrm{kg}$, the rate at which heat is taken up by the water is

$$
\begin{gathered}
A(\mathrm{l}-s) \rho^{\prime \prime} u^{\prime \prime}(759.4-36.5-0.1) \\
=A \times 0.5 \times 0.462 \times 1,003 \times 722.8 \\
\simeq 1.675 \times 10^{8} \mathrm{~A} \mathrm{kcal} / \mathrm{sec}=1.675 \times 10^{8} \mathrm{~A} \mathrm{cal} / \mathrm{sec} .
\end{gathered}
$$

If we divide this by $q$ we find that per second a surface of

$$
1.675 \times 10^{8} \times A / 0.975 \times 1.72 \times 10^{8} A \mathrm{~cm}^{2}
$$

must be available.

There enters the mass of water,

$A s \rho^{\prime} u^{\prime} \mathrm{kg} / \mathrm{sec}=5,000 A \mathrm{~kg} / \mathrm{sec}=5 \times 10^{6} A \mathrm{~g} / \mathrm{sec}$,

which has the volume $5 \times 10^{6}$

$$
A \mathrm{~cm}^{3} / \mathrm{sec}\left(\rho^{\prime}=1,000 \mathrm{~kg} / \mathrm{m}^{3} \text { and } u^{\prime}=10 \mathrm{~m} / \mathrm{sec}\right) \text {. }
$$

It thus follows that per $\mathrm{cm}^{3}$ of water we must have a surface area of

$$
1.72 \times 10^{8} / 5 \times 10^{6}=34.4 \mathrm{~cm}^{2} / \mathrm{cm}^{3} .
$$

When the water is dispersed into drops of radius $R$, the ratio of area to volume is $3 / R$. Hence we require drops of a radius not larger than $0.104 \mathrm{~cm}$, that is, drops of a diameter of about $2 \mathrm{~mm}$.

${ }^{4}$ In this formulas $A$ is expressed as $\mathrm{m}^{2}$. However, this does not effect the results since $A$ finally drops out. 
When the displacement of the surface must be taken into account, we assume (following Kolodner [2]) that the surface at time $t$ finds itself at a position,

$$
X=2 b \sqrt{\kappa t} .
$$

We now must have $T=T_{s}$ for $y=-X=-2 b \sqrt{\kappa t}$. Instead of (13) this gives,

$$
T_{s}-T^{\prime}=a(1+\operatorname{erf} b) .
$$

A second condition relating $a$ and $b$ is found by considering the balance between the heat liberated by the condensation and the heat flowing to the interior; it can be written,

$$
q=-\lambda\left(\frac{\partial T}{\partial y}\right)_{y=-x}=\rho L \frac{d X}{d t}=\rho L C \sqrt{\frac{\kappa}{t}},
$$

where $L=H^{\prime \prime}-36.5=603 \mathrm{kcal} / \mathrm{kg}=602 \mathrm{cal} / \mathrm{g}$.

With (12) and (16) we obtain

$$
\frac{\lambda a}{\sqrt{\pi \kappa t}} \exp \left(-b^{2}\right)=\rho L b \sqrt{\frac{\kappa}{t}}
$$

The time factor drops out, and with $\lambda=\rho C_{\kappa}$ we find,

$$
a=\sqrt{\pi} b e^{b^{2}} \frac{L}{C}
$$

Substituting this into (17) we arrive at

$$
b e^{b^{2}}(1+\operatorname{erf} b)=\frac{C\left(T_{s}-T^{\prime}\right)}{L \sqrt{\pi}} .
$$

Now with the data used above

thus

$$
C\left(T_{s}-T^{\prime}\right) / L \sqrt{\pi}=0.068 ;
$$

$$
b=0.064 \text {, and } a=68.8^{\circ} \mathrm{C} .
$$

From (18) we now obtain

$$
q_{t}=2 \rho L \mathrm{C} \sqrt{\kappa t} \cong 2.90 \sqrt{t} \mathrm{cal} / \mathrm{cm}^{2} .
$$

Again taking $t=0.1$ we find

$$
q_{t}=0.916 \mathrm{cal} / \mathrm{cm}^{2},
$$

instead of $0.975 \mathrm{cal} / \mathrm{cm}^{2}$ as given by (15a).

It appears from these calculations that the effect of the condensation of water upon the surface makes the heat flow to the interior somewhat smaller, although the difference remains below 10 percent.

Since it is necessary to disperse the water into fine drops in order to guarantee a sufficient condensation area, the calculations must be repeated for a spherical surface. This has been done only for the case where the displacement of the surface is neglected, in view of the mathematical difficulties involved in a more complete calculation. In this case it appears that with spherical drops the heat flow to the interior is smaller than with a plane surface. Probably the effect of the condensation upon the surface will agein give a further reduction by at most 10 percent.

Although the calculations cannot easily be made precise, they make it possible to obtain an estimate for the total surface area needed for the water entering into the mixing chamber per second, in order to allow the condensation of all the steam entering in the same period, when it is assumed that each water droplet will stay in the mixing chamber not over 0.1 sec. Fine dispersion of the water is necessary, in such a way that the drop size should be of about $2 \mathrm{~mm}$ in diameter. When this cannot be obtained, much more time must be allowed for the condensation.

\section{Equations of Motion for the Water Drop- lets}

Provisional equations have been developed for the motion of the water droplets in the mixing chamber, in order to find their speed as a function of the distance traversed. This is needed for the determination of the cross-sectional area which the mixing chamber must have at various distances from its entrance.

For this purpose it is assumed that the water has already been dispersed into fine drops and it is supposed that condensation takes place on these drops, so that no new drops are formed.

The speed of the water drops will be denoted by $u^{\prime}$; this speed increases with time, and we can also consider $u^{\prime}$ to be a function of the coordinate $x$ measured along the axis of the mixing chamber. We then can write for the drops, $d x=u^{\prime} d t$, and express their acceleration as, $d u^{\prime} / d t=u^{\prime}\left(d u^{\prime} / d x\right)$.

The speed of the steam will be denoted by $u^{\prime \prime}$. Also this speed can be a function of $x$.

We assume that the mixture of steam and water retains a constant pressure, and that the steam retains a constant temperature $T^{\prime \prime}$. The density of the steam, $\rho^{\prime \prime}$, will then be constant. The temperature of the water droplets, on the other hand, increases in consequence of the condensation of steam upon them. The density of the water drops $\rho^{\prime}$ will be considered as constant.

We shall write $A_{x}$ for the sectional area of the mixing chamber at the position $x$. Let the number of water drops per unit volume at $x$ be $n$; the number of drops crossing a section of the chamber per second is then given by,

$$
N=A_{x} n u^{\prime} .
$$

As mentioned it is supposed that no new drops are formed; when the state of motion is stationary the quantity $N$ must be a constant (independent of $t$ and $x$ ).

The volume of a drop will be written, $w=4 \pi R^{3} / 3$.

The mass of steam condensing on a single drop in unit time will be denoted by $M$, which may be a function of $x$. We then have,

$$
\rho^{\prime} d w / d t=M .
$$


The speed of the drops increases in consequence of the momentum gained from the condensing steam. This momentum is given by $M u^{\prime \prime}$ per second. It is possible that there is also a frictional force $f$ acting on the drops in surplus of the direct gain of momentum (it may be, however, that a closer analysis of the phenomenon of condensation will lead to the result that $f=0$, since the steam in the neighborhood of the drop will flow towards the drop, so that there will be no appreciable shearing effect at the surface of the drop).

Keeping both the direct transfer of momentum $M u^{\prime \prime}$ and the frictional force $f$ in the equations, we obtain for a single drop,

$$
\rho^{\prime} d\left(w u^{\prime}\right) / d t=M u^{\prime \prime}+f,
$$

from which, with the aid of (22),

$$
\rho^{\prime} w d u^{\prime} / d t=M\left(u^{\prime \prime}-u^{\prime}\right)+f .
$$

To form the conservation equations for the mixture of steam and drops we observe that the part of any section $A_{x}$ taken in by water is given by $A_{x} n w$, while the part taken in by steam is $A_{x}(1-n w)$. Complete condensation will have occurred when $n w$ has become equal to unity.

The equation of continuity takes the form,

$$
A_{x} n w \rho^{\prime} u^{\prime}+A_{x}(1-n w) \rho^{\prime \prime} u^{\prime \prime}=\text { constant }=K_{1} .
$$

The equation of momentum becomes (since the pressure is constant),

$$
A_{x} n w \rho^{\prime} u^{\prime 2}+A_{x}(1-n w) \rho^{\prime \prime} u^{\prime \prime 2}=\text { constant }=K_{2} .
$$

The equation of enthalpy transport can be added to these equations; it can be used to find the temperature of the drops. We shall omit it here.

From eqs (25) and (16) we deduce,

$$
A_{x} n w \rho^{\prime} u^{\prime}\left(u^{\prime \prime}-u^{\prime}\right)=K_{1} u^{\prime \prime}-K_{2} .
$$

With the aid of (21) this can be written,

$$
N \rho^{\prime} w\left(u^{\prime \prime}-u^{\prime}\right)=K_{1} u^{\prime \prime}-K_{2} .
$$

Differentiation with respect to the time gives,

$$
\begin{gathered}
N \rho^{\prime}\left(u^{\prime \prime}-u^{\prime}\right)(d w / d t)+N \rho^{\prime} w\left(d u^{\prime \prime} / d t\right)-N \rho^{\prime} w\left(d u^{\prime} / d t\right) \\
=K_{1}\left(d u^{\prime \prime} / d t\right),
\end{gathered}
$$

from which,

$$
\left(K_{1}-N \rho^{\prime} w\right)\left(d u^{\prime \prime} / d t\right)=-N f .
$$

It follows that the speed of the steam $u^{\prime \prime}$ changes only if there is an extra frictional force $f$.
Equations (25), (26), and (21) can be used to express $A_{x}$ and $n$ as functions of the other variables,

$$
\begin{aligned}
& A_{x}=\frac{\left(\rho^{\prime} u^{\prime}-\rho^{\prime \prime} u^{\prime \prime}\right) K_{2}-\left(\rho^{\prime} u^{2}-\rho^{\prime \prime} u^{\prime \prime 2}\right) K_{1}}{\rho^{\prime} \rho^{\prime \prime} u^{\prime} u^{\prime \prime}\left(u^{\prime \prime}-u^{\prime}\right)}, \\
& n=\frac{N \rho^{\prime} \rho^{\prime \prime} u^{\prime \prime}\left(u^{\prime \prime}-u^{\prime}\right)}{\left(\rho^{\prime} u^{\prime}-\rho^{\prime \prime} u^{\prime \prime}\right) K_{2}-\left(\rho^{\prime} u^{\prime 2}-\rho^{\prime \prime} u^{\prime \prime 2}\right) K_{1}} \\
& =\frac{\left(K_{1} u^{\prime \prime}-K_{2}\right) \rho^{\prime \prime} u^{\prime \prime}}{w\left[\left(\rho^{\prime} u^{\prime}-\rho^{\prime \prime} u^{\prime \prime}\right) K_{2}-\left(\rho^{\prime} u^{\prime 2}-\rho^{\prime \prime} u^{\prime \prime 2}\right) K_{1}\right]}
\end{aligned}
$$

The central problem is situated in the following three equations,

$$
\begin{aligned}
d w / d t & =M / \rho^{\prime} \\
d u^{\prime} / d t & =\left[M\left(u^{\prime \prime}-u^{\prime}\right)+f\right] / \rho^{\prime} w \\
d u^{\prime \prime} / d t & =-f /\left(K_{1} / N-\rho^{\prime} w\right) .
\end{aligned}
$$

If we attempt to neglect $f$, the last equation gives $u^{\prime \prime}=$ constant. We then obtain from the other two equations,

$$
d w / d u^{\prime}=w /\left(u^{\prime \prime}-u^{\prime}\right),
$$

the integral of which is,

$$
w\left(u^{\prime \prime}-u^{\prime}\right)=\text { constant } .
$$

If we know the volume of the individual water drops at the entrance of the mixing chamber $(x=0)$, and if we make a scale for $u^{\prime}$ (we know that $u^{\prime}$ increases from the value $10 \mathrm{~m} / \mathrm{sec}$ to the value 54.5 $\mathrm{m} / \mathrm{sec}$ with $s=0.5$ ) we can find the course of $w$ as a function of $u^{\prime}$.

Equation (30) then gives the corresponding value of $n$. When $n w=1$, the process is completed. Finally eq (29) would give the cross-sectional area $A_{x}$ as a function of $u^{\prime}$.

What remains is to find the relation between $u^{\prime}$ and $x$. This is determined by the equation

$$
d u^{\prime} / d x^{*}=\left(d u^{\prime} / d t\right) / u^{\prime}=M\left(u^{\prime \prime}-u^{\prime}\right) / \rho^{\prime} u^{\prime} w,
$$

where $d u^{\prime} / d t$ is obtained from (23) with $f=0$. In order to integrate this equation it is necessary to know $M$, and this must follow the analysis of the condensation process.

\section{References}

[1] P. Chiarulli and R. F. Dressler, Condensation interfaces in two-phase flows, J. Appl. Phys. 28, 990 (1957).

[2] I. I. Kolodner, Free boundary problem for the heat equation with application to problems of change of phase, Comm. Pure Appl. Math. IX, 1 (1956).

Washington, September 11, 1957. 